\section{Teorías y metáforas sobre desarrollo territorial}

\author{
Sergio Boisier
}

\section{Cuestiones generales.}

La semilla de un árbol difícilmente prosperará y dará frutos si cayó, por acaso o por intención, en un terreno seco, yermo, infértil; por el contrario, si el pequeño espacio geográfico que necesita para su desarrollo posee tierra de buena cali-

Director de la Dirección de Políticas y Planificación Regionales del Instituto Latinoamericano y del Caribe de Planificación Económica y Social (ILPES). dad, humedad y adecuada proporción de sales y minerales, la semilla se transformará en planta y ésta en árbol y éste producirá flores, frutos y vástagos y el proceso de nacimiento, desarrollo y reproducción se hará permanente en el tiempo.

La pequeña, y más aún, la micro empresa, generalmente familiar, requiere, análogamente, condiciones "ambientales" favorables para su desarrollo. Inserta en un medio hostil, no prospera o la prosperidad se hace tremendamente difícil. No es por nada que ha surgido en los últimos años todo un vocabulario (almácigos, semilleros, cunas, guarderías, etc.) usado para describir distintos mecanismos para "acunar" pequeñas empresas nacientes mediante el fortalecimiento de su medio externo.

El nivel de autorealización de un individuo a lo largo de su vida depende críticamente de la calidad del entorno en el que el individuo se desenvuelve. Precisamente, la evaluación que cada persona hace, de tiempo en tiempo, acerca de las posibilidades que ofrece su entorno inmediato para la realización de sus esperanzas, configura una de las razones básicas que se sitúan detrás de las decisiones migracionales, cuando tal evaluación es negativa.

Sea en la misma naturaleza, sea en el plano económico, sea en el plano social, el éxito de una unidad, de una célula básica de una estructura que posteriormente se diluye en la dimensión macro, el bosque, el tejido productivo, la comunidad, depende decisivamente de la estructura y del comportamiento de su entorno más inmediato, de carácter social desde luego (otros árboles para la fertilización cruzada, otras empresas para configurar matrices de insumos y productos, y otras personas en tanto el ser humano es gregario por naturaleza), y de carácter territorial.

El entorno territorial es factor clave del desarrollo. Bajo diferentes fórmulas administrativas y jurídicas del entorno territorial, la comuna, la pro- 
vincia, la región, el país, el mundo; la calidad del territorio determina el desarrollo de las estructuras sociales pertinentes en cada escala. El mundo o el globo terráqueo es importante para las naciones y para las corporaciones globales, el país lo es para las organizaciones de escala nacional y para las instituciones (normas y reglas, formales o no) de ese ámbito, las regiones o provincias o comunas, ámbitos más cotidianos, más proxémicos, son determinantes en el desempeño de todo aquello que las personas ven como más inmediato (empleo, educación, salud, vivien$\mathrm{da}$, etc.). Estas distintas categorias territoriales no son independientes; bien por el contrario, se articulan entre sí en una verdadera "jerarquía anidada", puesto que cada nivel de ella impone restricciones de variado alcance sobre los niveles inferiores. Pero una jerarquía anidada no implica una sobredeterminación de carácter sistémico que anule los grados de libertad a medida que se desciende en la jerarquia.

Como se ha dicho, lo pequeño, hermoso o no, es importante para el desarrollo. En términos territoriales, la comuna es importante para la prestación de servicios y para el fomento económico local, la región (utilizando este término sin mayores precisiones por el momento) es importante para el logro de funciones más complejas, que tienen que ver con el desarrollo contemporáneamente entendido. En verdad, en el marco de una creciente globalización, marco en el cual los Estados nacionales tienden a reconfigurarse con menos autonomia, los territorios organizados, regiones, provincias, comunas y ciudades, aparecen como nuevos actores en la competencia internacional por capital, por tecnología y por nichos de mercado. El eje central del soporte del desarrollo se desplaza "de arriba abajo" en términos territoriales e institucionales.Como lo dice Naisbitt (1997): "Lo pequeño es bello, pero lo real6 mente bello en este contexto [la globalización] es la escala apropiada".

La globalización, como se ha repetido en varias oportunidades, obliga a los países a una operación de cirugía mayor, como es la apertura externa, con no pocos costos internos. Si la apertura externa a su vez obliga a competir en forma "competitiva" (por contraposición a una competetencia no competitiva o espuria), es difícil imaginar alguna posibilidad de éxito en el duro escenario actual si se pretende competir usando estructuras decisionales centralizadas que, por ello mismo, carecen de la velocidad, flexibilidad, maleabilidad y complejidad requeridas por la contemporaneidad. Según Warren Bennis (1997), estas necesidades se plantean también en el ámbito organizacional privado, ya que las compañias de todo el mundo se están convirtiendo en PALs (Pooling, Allying and Linking), citando la expresión acuñada por Rosabeth Moss Kanter. Así es que la descentralización, una cuestión demandada hasta ahora por razones eminentemente políticas, comienza a ser ofertada por razones de eficiencia económica competitiva.

Ello explica en parte la generalizada y creciente tendencia, observable en América Latina y en otras partes, de traspasar la responsabilidad de hacer gobierno desde el nivel de gobierno nacional/central a varias instancias de gobiernos subnacionales, nuevos o de antigua data. La expresión "hacer gobierno" ahora, en el marco de la globalización neo-liberal, debe ser entendida como una función muy cercana a la función de fomento del desarrollo. Parafraseando a Paulo VI, ("el desarrollo es el nuevo nombre de la paz") ahora podría decirse que desarrollo es el nuevo nombre de gobierno.

En este nuevo marco, neo-liberal por un lado, y descentralista por otro, aumenta la sensación de que algo anda mal, de que las cosas no están funcionando de la manera supuesta, que hay crecimiento económico, tal como habitualmente se 
le define, pero que el desarrollo, no lo acompaña, sigue siendo esquivo, como lo denominase Marshall Wolfe. Con más y más frecuencia se observa que regiones cuya constelación de recursos naturales y humanos haría prever, mediando una conducción adecuada, el surgimiento de un vigoroso proceso de desarrollo, de ampliación de oportunidades, de ampliación de la libertad, de ampliación de opciones, de mayor justicia y de creciente ética en las relaciones inter-personales y también en relación al medio ambiente, siguen sin desarrollarse, con o sin crecimiento económico.

Por supuesto que no hay explicaciones "simples" para entender la falta de desarrollo, si es que se entiende la complejidad del propio concepto de desarrollo. Desde este punto de vista nuestra cultura profesional, tan inmersa en el paradigma científico positivista no ayuda a trabajar con la complejidad; hay que agregar a ello nuestra fuerte tendencia a privilegiar la entropía por sobre la sinergía al momento de actuar en la práctica y el tradicional desrespeto hacia los actores, hacia las instituciones y hacia la cultura en nuestra aproximación al desarrollo. Teniendo presente las afirmaciones anteriores, es posible, sin embargo, llamar la atención a una cuestión particular, pero de amplísima repercusión en la totalidad y cuya carencia o cuyos déficits parecen apuntar a un asunto de crucial importancia desde el punto de vista de la acción: el conocimiento.

En concreto lo que acá se plantea es que el proceso de traspasar la responsabilidad de gobernar, de "arriba abajo", capacidad que, como se dijo, ahora casi se confunde con la capacidad para fomentar el desarrollo, se está llevando a cabo sin mediar una creación de conocimiento pertinente, como si el proceso de gobierno a escala sub-nacional fuese un proceso de gobierno "en chico", como si el desarrollo fuese un fenó- meno (matemáticamente) contínuo en el territorio, como si no se produjesen cambios estructurales cualitativos incorporados en el cambio cuantitativo de escala. La "fractalidad", por así decirlo, no se aplica a la gestión del desarrollo.

Información y conocimiento, son, desde este punto de vista, elementos claves del desarrollo territorial. La asociatividad y el poder político colectivo, otros dos elementos también cruciales del desarrollo en cualquier territorio, dependen fuertemente de la información y del conocimiento. En un reciente trabajo del ILPES, su autor, Lira(1997), sostiene con razón que se observa una carencia en las administraciones y gobiernos subnacionales de tecnologías de la información, cuestión que les permitiría comportarse como organizaciones inteligentes (subrayado de este autor). Hay que precisar, sin embargo, que se trata de una doble carencia: tecnológica, por un lado, para generar, recolectar y procesar la información, y cognitiva por otro, para transformar precisamente la información en conocimiento.

De los muchos segmentos de conocimiento necesarios en cualquier proceso societal, como lo es el desarrollo, no puede haber otro de importancia mayor que la epistemología del desarrollo territorial, es decir, precisamente la base científica del conocimiento sobre la fenomenologia del desarrollo territorial, en otras palabras, no hay conocimiento más importante que aquél que entrega luz sobre los factores determinantes del desarrollo. En todo esfuerzo contemporáneo de fomento al desarrollo territorial hay que responder explícitamente a una pregunta central: $i$ de qué depende el desarrollo de un territorio en un contexto de economías de mercado, abiertas y descentralizadas? Si no es posible responder a esta pregunta, es claro que todo intento de intervenir sobre el proceso latente, a fin de desatarlo y/o acelerarlo, será un intento "azaroso" que dará resultado "si se tiene buena suerte". 
Pero, como se verá más adelante, el acumular conocimiento sobre la causalidad del fenómeno del desarrollo, es decir, el llegar a identificar un conjunto de factores causales (desde aquellos relativamente clásicos, como recursos naturales hasta los de más moderna concepción, como capacidad de crear progreso técnico) no será suficiente para desatar un proceso autosustentante de desarrollo.

La clave del desarrollo, según se entiende ahora, radica en la sinergía que puede generarse mediante la articulación densa e inteligente de los factores causales. Esto a su vez presupone un complejo y permanente proceso de coordinación de decisiones que pueden ser tomadas por una multiplicidad de agentes o actores cada uno de los cuales dispone de un amplio abanico de opciones decisionales, que deben ser transformadas en una matriz decisional dirigida al desarrollo.

La construcción (social) de esta matriz es en si misma un proceso de elevada complejidad, sobre todo, cuando su construcción se entiende como un proceso democrático y participativo, que prescribe, por ello mismo, imposiciones desde arriba.

La única manera de lograr esto en la práctica es mediante la generación sistemática de información, elemento básico de la coordinación, que es, a su vez, un acto entre pares. La preparación del proyecto colectivo, o societal de desarrollo, o proyecto político, es la manera de generar y circular un flujo permanente de información entre los "factores" del desarrollo (actores, organizaciones, etc.) de manera de construir sistemáticamente la matriz aludida. La configuración de una mesa sinergética (por analogia a una mesa de concertación), responsabilidad fundamental del gobierno respectivo, se basa en su potencialidad de generación de información que reduzca
Hay tres campos interrelacionados de conocimientos que deben ser explorados y sacados a luz a fin de poner en juego un programa eficiente de fomento del desarrollo territorial.

En primer lugar, a medida que se desciende en la escala geográfica de operación, mayor es la apertura sistémica del territorio en cuestión, ya que no se encuentran, en tales niveles, los mecanismos jurídicos y administrativos que "cierran" al país, como aduanas, fronteras, etc.. Esta mayor apertura de un territorio subnacional versus su contrapartida nacional (país) hace del entorno del sistema, un componente muy fundamental en la operación del propio sistema; el intercambio entre el sistema y su entorno y la matriz decisional que opera en el entorno pueden adquirir más importancia que los propios elementos internos, desde el punto de vista de los impulsos dinámicos al crecimiento y al desarrollo. Pero no se trata sólo de las nuevas situaciones que se crean al descender en la escala territorial; se adicionan a ellas los mismos cambios ocurridos en el entorno, para cualquier territorio, cambios de naturaleza tecnológica, económica, política y social. De hecho, se está frente a un nuevo entorno cuyo conocimiento es imprescindible, precisamente para descubrir las nuevas formas de articulación y los nuevos elementos configurativos del entorno. Por eso se habla de la creación de un nuevo entorno para el desarrollo territorial, que no es otra cosa, que un nuevo conocimiento. Obsérvese y ésta es una observación estrictamente latinoamericana-que hace más de veinticinco años (nada menos que un cuarto de siglo !) que Gutierrez, Ortiz y Villamil (1971), tres destacados planificadores portorriqueños, publicaron un importante trabajo llamando la atención hacia los problemas que se generan en la planificación de sistemas abiertos; sin embargo, se sigue trabajando a nivel subnacional como si se operase en sistemas cerrados. 
En segundo lugar, el propio cambio en el entorno provoca un cambio en "el interno" (una libertad de lenguaje para hacer referencia a lo endógeno), aparte del hecho de que "el interno" tiene también su propio proceso de cambio. Esto se puede ilustrar de la siguiente manera: el paso de economias cerradas a economias abiertas torna obsoletos ciertos instrumentos de política económica muy usados en el fomento regional, como los aranceles diferenciados por ejemplo (un cambio en el entorno lleva a un cambio en el interno al invalidar un "factor" de localización y de crecimiento); pero paralelamente, aparecen nuevos factores internos vinculados al desarrollo, como por ejemplo, los recursos psicosociales (nuevos en el sentido de una revalorización de ellos), que anteriormente ni siquiera eran identifjcados, con la notoria excepción de A. Hirschmann y su alusión a los "recursos morales" en el desarrollo. Esto lleva a la necesidad, entonces, de descubrir e inventar un nuevo conocimiento, que será puesto al servicio de la creación de un nuevo interno" del desarrollo territorial.

Un nuevo entorno y un nuevo "interno" del desarrollo territorial configuran un nuevo paradigma, un nuevo marco cognitivo para el desarrollo del territorio. Pero para poder hablar correctamente de un "nuevo" paradigma, habrá que dejar transcurrir un cierto tiempo, en la medida en que un paradigma no sólo constituye una matriz puramente cognitiva, sino también una matriz de experiencias, obviamente empiricas.

El nuevo conocimiento, generado tanto especulativa como empíricamente, tiene como finalidad avalar y respaldar la operación más importante desde el punto de vista del desarrollo territorial: el diseño de una verdadera ingeniería de la intervención territorial, esto es, un proceso que, conociendo los factores causales del desarrollo, pueda incidir sobre ellos, potenciándolos y articulándolos mediante el uso de la inteligencia so- cial.

En tercer lugar, entonces, el diseño de una "ingeniería de la intervención" presupone el uso del nuevo conocimiento del entorno y del "interno" y requiere además, generar información y conocimiento de manera sistemática para alimentar la "mesa sinergética", es decir, para facilitar la coordinación de decisiones. La "ingeniería de la intervención" plasma en un proyecto político de desarrollo. ¿ Por qué un "proyecto político" y no simplemente un "plan" o una "estrategia" ? Por varias razones, las principales de ellas tienen que ver con el reconocimiento de que en la práctica una propuesta de desarrollo es abordada por diferentes actores con diferentes lógicas y pautas conductuales, no sólo con la racionalidad instrumental de la economía propia de las ideas de "plan" y de "estrategia", también porque lo que se pone en juego no son sólo recursos económicos de mercado, sino recursos no transables, de naturaleza no económica (los que en su articulación generan lo que Putman llama "capital social" en su estudio sobre Italia) y también porque el diseño de un proyecto colectivo implica trabajar con esquemas constructivistas e intersubjetivos, que escasamente pueden ser aprehendidos por la economía pura. El trabajo de diseñar y ejecutar un proyecto colectivo de desarrollo es en todo equivalente a producir coordinación y seguimiento permanente, así como rediseño igualmente permanente. No se trata de procesos de ingeniería real, de llegar a un producto acabado en un plaza determinado, sino de procesos casi asintóticos, de aproximación contínua. El proyecto mismo es una "pieza de información" y su propia construcción es generación cotidiana de información y conocimiento. La construcción colectiva de este proyecto genera dos resultados importantísimos: a] saca la cuestión del desarrollo del campo del azar para llevarlo al campo de lo probabilístico y; b] transforma una masa entrópica de decisiones 
en una matriz sinérgica de decisiones alineadas con el desarrollo.

En definitiva, se trata de crear nuevo conocimiento sobre el medio externo de cualquier territorio, sobre los factores desencadenantes de su propio crecimiento y sobre todo, de su propio desarrollo, y sobre la forma de organizar o diseñar una intervención destinada precisamente a desatar y/o acelerar el desarrollo, que no es, ciertamente el desarrollo del territorio per se, si no el desarrollo de las personas humanas que habitan en él. La necesidad de este stock de conocimiento nuevo deriva principalmente de la obsolescencia del conocimiento previo, obsolescencia derivada tanto de la revolución científica y tecnológica como también de alcanzarse un estadio superior del derecho colectivo al desarrollo. El desarrollo no es el privilegio de unos pocos; es el derecho de todos, que se alcanza mediante procesos colectivos basados en el conocimiento, en la asociatividad, en el liderazgo político.

¿Por que hablar de teorías y metáforas? ¿Acaso no es el desarrollo una cuestión eminentemente "práctica" que debiera estar preferentemente en manos de los hombres de acción más que en las cabezas de los hombres de reflexión?

Ya es una osadía emplear la palabra "teoría" en el título de cualquier trabajo académico, salvo, quizás, si el autor proviene del campo de la filosofía. ¿Es posible hablar de "teoría" en materia de desarrollo territorial? Desde luego, si se entiende, clásicamente, teoría como una construcción especulativa del espíritu, que relaciona consecuencias con principios: por oposición a la práctica, en el orden de los hechos, (lo que es objeto de un conocimiento desinteresado, independiente de sus aplicaciones); por oposición a la práctica, en el orden normativo, (lo que constituiria el ideal); por oposición al conocimiento vulgar, (lo que es objeto de una concepción metódica, sistemáticamente organizada y que depende de convenciones científicas que no pertenecen al sentido común); por oposición al conocimiento cierto, (construcción basada en hipótesis); por oposición al detalle, (amplia sintesis que se propone explicar gran cantidad de hechos relacionados). Cualquiera sea la acepción privilegiada, la relación causa/efecto que se encuentra siempre detrás de todas las acepciones anteriores, es fundamental para conferir racionalidad a todo acto (político) de intervención en cualquier campo. No parece sensato a nadie, concebir el fomento del desarrollo territorial como un acto casuístico, que se explica en su totalidad por sí mismo, por su tiempo y circunstancia. ¿Es conveniente hablar de "teoría" en este mismo campo? Sí, precisamente para encontrar esa racionalidad que eleve la probabilidad de tener éxito en las intervenciones dirigidas a fomentar el desarrollo.

Octavio lanni (Teorias y metáforas de la globalización) dice con respecto a las metáforas: "La metáfora está siempre en el pensamiento científico. No es un artificio poético, sino una forma de sorprender lo imponderable, fugaz, recóndito o esencial, oculto en la opacidad de lo real. La metáfora combina reflexión e imaginación. Descubre lo real de forma poética, mágica. Aunque no lo revele todo, y esto puede ser imposible, siempre revela algo fundamental. Capta una connotación insospechada, un secreto, lo esencial, el aura. Tanto asi que ayuda a comprender y explicar al mismo tiempo que a captar lo que hay de dramático y épico en la realidad, desafiando la reflexión y la imaginación. En ciertos casos, la metáfora descubre el pathos oculto en los movimientos de la historia".

Teorias y metáforas para entender y desentrañar procesos que se nos escapan de las manos. Teorías y metáforas para comprender que el crecimiento es condición necesaria, pero nunca suficiente, del desarrollo; que el crecimiento progresivo puede coexistir con un desarrollo regre- 
sivo; que ambos procesos mantienen entre si articulaciones rizadas y no lineales, y que por tanto, la mera racionalidad instrumental de la ciencia económica difícilmente puede dar cuenta de ellas. Teorías y metáforas para entender que la clave ha estado siempre en las personas y en su ethos individual y en su pathos colectivo. Teorias y metáforas para descubrir que el desarrollo es un ideal asintótico al eje de las realizaciones colectivas, un miltoniano y no recuperable "paraíso perdido", pero cuya búsqueda jamás debe ser abandonada, so pena de perder toda capacidad de construir utopias. De nuevo lanni : "De metáfora en metáfora se llega a la fantasía, que ayuda a volver a encantar al mundo, para producir la utopia".

No hay receta posible para alcanzar el desarrollo de un territorio dado. El desarrollo tiene mucho de heurístico, de descubrimiento permanente, de rizo, de creación de futuro recogiendo lo valioso del pasado, pero sin la pretención de construir un futuro como una extrapolación del pasado.

Si bien no hay un recetario para entregar a quien tiene la responsabilidad de conducir un intervencion, hay si dos afirmaciones importantes: si el desarrollo se encuentra en nuestro futuro, no será con las ideas del pasado que lo alcanzaremos; si el desarrollo es un producto de la propia comunidad, no serán otros, sino sus propios miembros quienes lo construyan

\section{Un conocimiento sistémico para la gestión territorial en la globalización.}

Teorias y metáforas para ser usadas en una gestión territorial de "mejor calidad", la Deming, tratando de alcanzar la "calidad total" para que la gestión esté realmente al servicio de los "bipedos implumes"que habitan las regiones $u$ otros territorios, para que en el Siglo XXI las personas no sean sólo consumidores, para que sean también ciudadanos de pleno derecho. Teorias para dar forma a un conocimiento a ser utilizado en un contexto de globalización y de creciente apertura externa, puesto que la gestión territorial habrá de plantearse en tal contexto, contexto de cambios múltiples. Teorías que apunten no sólo a cuestiones procedimentales, como está ahora de moda en el traspaso apresurado de tecnologías administrativas desde el sector privado al público, si no teorías sustantivas que puedan desentrañar la complejidad de la estructura del fenómeno en cuestión y de su dinámica.

A la globalización vista como "emergencia sistémica" (en la expresión de F. Bervejillo), se debe oponer entonces, un "sistema cognitivo" requerido para intentar ser sujeto interviniente en ella y no un objeto meramente pasivo o un instrumento. Hay que recordar que tal vez el principal efecto de la globalización es la creación de una red mundial de territorios, organizaciones y personas que se configura rápidamente como la función generatriz del crecimiento económico en el Siglo XXI. De aquí se desprende una idea-fuerza, un slogan imperativo: ¡Hay que estar en la red! Si se está, se crece, si no se está, no se crece. A la crudeza de la afirmación anterior hay que agregar sin embargo, una sutileza importantísima: hay que estar y hay que saber estar. No es lo mismo tener un PC encima del escritorio que saber crear una página WEB o navegar en la supercarretera.

.Emplearé la expresión "sistema cognitivo" para denotar un conjunto de conocimientos de carácter más horizontal, más interdisciplinario que el contenido sugerido por el término "paradigma", entendido éste como un conocimiento más en profundidad sobre un campo específico de actividad. Es claro, sin embargo, que aquí nos ocuparemos de un "sistema cognitivo" reducido, que ecuaciona solamente algunos impactos territoria- 
les de la globalización con una manera de enfrentarios proactivamente. En la idea de la globalización como "emergencia sistémica" hay implícita una cierta recursividad y por tanto son distinguibles numerosos subsistemas o numerosas "emergencias sistémicas" de variada escala, a las cuales se oponen también diversas escalas de "sistemas cognitivos", siempre en conformidad con el principio de la variedad necesaria de Ashby.

Desde el punto de vista territorial entonces, ¿qué conocimientos se requieren para "saber estar en la red" y para operar en la globalización ? Sugiero responder esta pregunta diciendo que, por lo menos, se requieren dos cuerpos de conocimientos para que el territorio y el abanico de nuevas regiones futuras enfrenten positivamente la globalización. El primero de ellos referido al papel del Estado contemporáneo en su relación con su propio territorio y el segundo configurado por los tres campos cognitivos anotados anteriormente (entorno, interno, intervención). La globalización puede ser, para muchos territorios, lo que la lámpara es a la mariposa nocturna: una atracción fatal, si la aproximación (a la llama, a la globalización) es poco cuidadosa, poco inteligente. $Y$, ¿quién puede proveer la inteligencia social para una aproximación que no sea fatal, si no es el propio Estado?

En esa perspectiva, por un lado, el pais como un todo requiere un conocimiento específico que de forma a una politica regional en un contexto de globalización, que permita la interacción con la nueva geografía emergente de la globalización; por otro, cada una de las nuevas regiones que se consoliden a futuro ( $\mathrm{y}$ algunas de ellas podrian coincidir por completo con las actuales) requiere un conocimiento específico que le permita maximizar su potencial de crecimiento y desarrollo, para mejorar su inserción poniendo en juego nómico y del desarrollo, particularmente poniendo en juego la capacidad sinérgica del conjunto de ellos. Ambas formas de conocimiento han sido elaboradas por este autor en oportunidades recientes (1996/b, 1997), de manera que acá se hará una síntesis de ellas.

Sin una política regional modernamente concebida, lo primero que ocurrirá es que el territorio nacional asumirá un "orden" dictado estrictamente por la lógica del capital en su proceso de penetración y expansión mundial; este orden es un orden por omisión, ya que el capital no opera con criterios territoriales sino con criterios de rentabilidad microeconómica. No por ello sin embargo, se dejará de producir un ordenamiento territorial; la cuestión que surge se relaciona con la coherencia de dicho ordenamiento con los intereses superiores de la sociedad, representados en el Estado y por el Estado.

Una política regional contemporánea, es decir, una política regional para el Siglo XXI, puede ser esquemáticamente visualizada como una matriz de cuatro vectores, cada vector configurando una política más específica y cada elemento vectorial representando un instrumento de politica.

Un primer vector corresponde al ordenamiento territorial, incluyendo instrumentos como: a] una división política-administrativa, que puede implicar cambios a la división vigente, pero que también puede no modificarla; b] una asignación de funciones a cada unidad de esa división, en el asi llamado "proyecto nacional"; c] una especificación de prioridades territoriales de desarrollo en el tiempo; d] una propuesta de un sistema de asentamientos humanos; e] una propuesta de mega-usos del suelo.

Un segundo vector corresponde a la descentralización política y territorial, con instrumentos como: a] arquitectura institucional y administrativa de cada unidad de la división político-adminis- 
trativa; b] reparto de competencias; c] fiscalidad; d] sistema de control y resolución de conflictos.

Un tercer vector de política corresponde a la política de fomento. Los instrumentos básicos son en este caso: a] ayuda a la competitividad; b] ayuda a la reconversión productiva; c] ayuda a la equidad y a la pobreza intra-regional; d] ayuda a la generación y difusión de conocimiento. Obsérvese cómo acá aparecen claramente en juego los principios de subsidiariedad y de solidaridad.

Un cuarto vector, finalmente, corresponde a la política de coherencia inter-regional, basada en el uso de instrumentos como los siguientes: a] modelización; b] procedimiento iterativo convergente de información y retroalimentación; c] solución de crecimiento económico coherente región/nación. Esta última política, muy instrumental, busca evitar que la descentralización se transforme en un verdadero caos de propuestas incoherentes emanadas de las regiones.

Una política regional eficiente necesariamente debe mantener estricta correspondencia con el "estilo global de desarrollo". Si tal estilo es economicista y eficientista, así también será la marca de la política regional, guste o nó. Hace casi veinte años que J. Hilhorst, en un importante Seminario Internacional sobre Estilos de Desarrollo y Estrategias Nacionales de Desarrollo Regional, celebrado en Bogotá en 1979, llamó la atención sobre este punto al comentar acerca de la ingenuidad de atribuir objetivos sociales a una politica nacional de desarrollo regional si ello no se correspondia con el "estilo" del desarrollo global. Desde este punto de vista hay que tener presente que hoy el Estado "apuesta" a las regiones que pueden contribuir más rápida y claramente al logro de los más importantes objetivos nacionales (crecimiento, competitividad, reconversión, equilibrio fiscal, etc.). En ese marco hay que encontrar un espacio legítimo para la solidaridad territorial; de otro modo, toda la estructura social comienza a ponerse al servicio exclusivo de los ganadores, que siempre son los menos aunque no siempre los mismos. Ahora que está de moda referirse a regiones "ganadoras" y regiones "perdedoras", es bueno no perder de vista que a priori no se sabe cuáles resultan ganadoras o perdedoras y que todas deben apostar a resultar ganadoras, so pena de transformar la condición de perdedor en una profesía autocumplida.

Poco es lo que se puede decir con respecto a este asunto en el caso de Chile, por ejemplo. En verdad no existe, por el momento, una política regional en el pais, aunque algunos elementos de sus distintos vectores componentes son reconocibles. La descentralización parcial, la propuesta (ya antigua) de división regional, el emergente fomento productivo, parecen constituir los únicos elementos reconocibles por el momento.

Hecha esta consideración es posible ir a la cuestión de un nuevo paradigma sobre desarrollo territorial, útil para la acción. Este paradigma, esta matriz cognitiva, está compuesta de dos grandes elementos: el nuevo entorno del desarrollo territorial (nuevas circunstancias y configuraciones del medio externo contra el cual hay que proyectar una propuesta) y el nuevo interno del desarrollo territorial, es decir, la causalidad actual del crecimiento económico y del desarrollo (si bien una mirada "hacia adentro" del territorio en materia de crecimiento llevará de inmediato a mirar también "hacia afuera", lo que no hace sino probar la complejidad del asunto).

El nuevo entorno del desarrollo territorial está conformado por los nuevos escenarios de ese mismo desarrollo. Un nuevo escenario contextual, construído a partir de los procesos de apertura externa y de apertura interna de los paises; un nuevo escenario estratégico, armado mediante los procesos de reconfiguración territorial y mediante el surgimiento de novedosas formas de gestión territorial y, finalmente, un nuevo escena- 
rio político, vinculado a la modernización del Estado y al surgimiento de funciones no tradicionales en la forma de hacer gobierno en el territorio.

El nuevo escenario contextual nace de la interrelación entre el proceso económico de apertura externa al cual los países son empujados por la globalización, y el proceso político de apertura interna al cual son también empujados los países, ahora por la fuerza de la descentralización. Globalización y descentralización, dos megatendencias que a su vez reconocen varios mecanismos impulsores. La globalización se explica, como se insinuó, por el nuevo modelo tecno-productivo que hace de la innovación permanente su razón de ser, un proceso que requiere recursos financieros en forma creciente y que genera productos de vida cada vez más corta, todo lo cual apunta a la conformación de un único mercado mundial, el "shopping center mundial", para recuperar el capital. A su vez, la mundialización del mercado ha exigido un nuevo orden internacional que en lo político se caracteriza por la "monopolaridad" norteamericana y en lo económico por la "tripolaridad" de los grandes acuerdos comerciales. La descentralización, por su lado, se explica a partir del "ambiente" creado por la conjunción de la Revolución Científica y Tecnológica (y sus efectos sobre la producción, las comunicaciones y los transportes), la reforma política del Estado, las demandas autonómicas de la sociedad civil, y las tendencias privatizadoras. La apertura externa obliga a la apertura interna, por razones de la velocidad necesaria para la competencia.

Para cualquier territorio, este nuevo escenario contextual implica la obligatoriedad, so pena de quedar condenado a formar parte del equipo de los "perdedores", de ubicarse en cuatro nichos de la contemporaneidad: el nicho de la competitividad, el nicho de la modernidad, el nicho de la equidad y el nicho de la participación.
Los dos primeros referidos a los bienes y servicios transables y los dos siguientes referidos a la población.

El nuevo escenario estratégico se construye en la intersección de las nuevas modalidades de configuración territorial y de las nuevas modalidades de gestión territorial. En relación a las primeras, hay que repetir que está en marcha el surgimiento de una nueva geografía, que se materializa tanto en el espacio geográfico como en el ciberespacio. La geografía política internacional está cambiando con rapidez en la década de los noventa y la geografía política nacional se triza y pugna por reacomodos incluso en los paises más consolidados. Surgen nuevas categorias regionales que rápidamente circulan desde el "paper" monográfico al arreglo organizacional e institucional en el terreno: regiones pivotales, en la base de nuevas jerarquias "anidadas", regiones asociativas, inclusive con "permiso" constitucional, y regiones virtuales, propias del Siglo $\mathrm{XXI}$, organizadas estratégicamente por sobre fronteras nacionales e internacionales, como se muestra o se propone en Argentina, Colombia y México, para citar sólo algunos ejemplos. Por otro lado, se busca hacer gestión territorial incorporando a ella las prácticas planificadoras de las grandes corporaciones privadas (planificación estratégica, calidad total, etc.) y se habla de regiones como cuasi-empresas al tiempo que en forma simultánea se reconoce en la acumulación de poder el principal desafío para el crecimiento y desarrollo en el territorio y ello se expresa en la idea de las regiones concebidas como cuasi-Estados.

Por último, el nuevo escenario político queda definido en términos de la necesaria modernización del Estado, vista ella desde la perspectiva de los propios territorios (un Estado moderno desde tal perspectiva es un Estado que hace conducción territorial tanto como conducción políti- 
ca) y de las nuevas funciones emergentes para todo gobierno territorial, funciones estrictamente políticas como el despliegue de una fuerte capacidad de negociación y funciones sociales como el despliegue de la capacidad de animación, para crear sinergía y para manejar la información entrópica.

En resumen, el "nuevo entorno" del desarrollo territorial obliga a pensar toda propuesta de futuro en función del posicionamiento en los mercados internacionales, en función de un papel más significativo de la propia sociedad civil, en función de un reparto más equitativo de las ganancias, con suficiente flexibilidad para acomodar el territorio en diferentes ámbitos y configuraciones territoriales, administrándolo como si fuese una organización empresarial, gobernándolo de manera de crear poder político, demandando al Estado una visión territorial de sí mismo, y entendiendo que una gestión contemporánea requiere crear "capital social" sin que ella se agote en el uso de los recursos materiales tradicionales.

Por otro lado, el "nuevo interno" del desarrollo territorial trata de explicar, contemporáneamente, los factores del crecimiento económico y los factores del desarrollo territorial.

El punto de partida de esta discusión está en el reconocimiento del carácter exógeno que, a partir de ahora, asumirá en forma cada vez más notoria el crecimiento de todo territorio, como consecuencia directa de la globalización que, para estos efectos, produce una creciente disociación entre la matriz decisional que está detrás de los factores del crecimiento y la matriz socio-económica local, al mismo tiempo que se reconoce el carácter endógeno del desarrollo, haciéndolo depender precisamente de esa misma matriz socio-económica citada.

Si se traen al territorio las más modernas teorías del crecimiento económico (denominadas de "crecimiento endógeno" y asociadas principal- mente a los nombres de R. Lucas y P. Romer), hay que admitir que el crecimiento económico territorial resulta ser una función de: a] el ordenamiento territorial del país (y el papel que asigna al territorio en cuestión); b] el cuadro de la política económica nacional ( $\mathrm{y}$ a los específicos efectos que dicho cuadro tiene en el territorio en cuestión); c] la acumulación de capital; d] la acumulación de conocimiento; e] la demanda externa; f] los recursos humanos. Puesto que en forma creciente -y ésto es tanto más cierto cuanto más pequeño es el territorio- el capital que pudiese generar proyectos y empleo en el territorio tendrá un origen externo, el conocimiento y el progreso técnico vendrán incorporados más y más en las máquinas importadas o será transferido en la cadena matriz/filial, las exportaciones y el gasto de no residentes radican afuera, la política económica y también la política de ordenamiento territorial son definidas por el Estado, la región o el territorio sólo pueden influir en esa matriz decisional, sin llegar jamás a controlarla (lo que no significa que no existan del todo casos de crecimiento endógeno, tanto por la simpleza de una estructura como, alternativamente, por la complejidad de ella).

Esta capacidad de influenciar decisiones exógenas descansa en la capacidad que pueda desarrollar el territorio para negociar y para promocionarse. Cuestiones complejas de carácter científico, político, social, semiótico, comercial, se encuentran detrás de la afirmación precedente. No menos importante en este contexto es la necesidad de un verdadero cambio cultural en relación al modo de atraer capital, pasando de actitudes pasivas (la cultura del trampero) a actitudes de elevada agresividad (la cultura del cazador). Con un capital crecientemente desterritorializado que circula por sobre países y fronteras y con una tecnología de iguales características, la radicación dependerá de las armas 
de pesca y caza que sean capaces de usar los territorios y de su habilidad (la "guerra fiscal" entre los Estados del Brasil no parece ser mal vista por los Gobernadores que creen saber luchar en ella, aunque el bien común aconsejaría una regulación federal de ella).

El esquivo desarrollo, en una visión "hirchmanniana", parece depender más de la articulación de los recursos, que de la existencia de cada uno de ellos en particular, o de sus recursos materiales. Se sugiere considerar los siguientes seis factores de desarrollo: a] recursos, entendiendo por ello cuatro categorias (materiales, humanos, cognitivos, psicosociales); b] actores, individuales, corporativos, y colectivos; c] instituciones, incluyendo las reglas del juego y las organizaciones para alinear este concepto con el pensamiento de D. North y la escuela institucional de desarrollo; d] procedimientos, de carácter societal, particularmente aquellos asociados a la gestión de gobierno, a la administración pública, y al manejo de la masiva información entrópica contemporánea; e] cultura, en una doble acepción, como concepto genérico construído sobre una cosmogonía y sobre una ética de particulares expresiones en el territorio en cuestión y la cual juega ahora en la competencia internacional posibilitando la generación de nichos comerciales particularizados basados en las expresiones concretas de dicha cultura (productos amparados en una denominación de origen, por ejemplo), y como concepto ligado al desarrollo (cultura de desarrollo) con los dos modelos polares que requieren de una virtuosa combinación, una cultura dominada por la competencia y el individualismo en un lado, o dominada por la solidaridad y la cooperación en el otro; f] entorno, esto es, la inserción del territorio en, y la articulación con, el Estado, con el mercado y, actualmente, con las nuevas modalidades (horizontales) de coopera-
Estos seis factores no son difíciles de encontrar en cualquier territorio organizado, naturalmente que con distinta fuerza. Lo importante es que el desarrollo no será el resultado de la mera presencia de ellos ni siquiera de una figurada "suma", sino de la articulación entre ellos. Esta articulación a su vez, puede ser de dos clases: difusa y sin una direccionalidad clara, en cuyo caso no se producirá el desarrollo, o bien, densa y direccionada, en cuyo caso el desarrollo se presenta en forma predecible. Más importante aún, una articulación densa y direccionada podría ser el resultado del azar (innumerables pruebas de acierto y error durante la historia), como lo sostiene por ejemplo A. Peyrefitte (1996) en relación a la primera revolución industrial, pero también tal articulación densa y direccionada puede resultar de una ingeniería de la intervención, o sea, de la aplicación de inteligencia social al conjunto de los factores (harina, agua y levadura no hacen el pan, sino media la amasandería). Esta ingeniería de la intervención descansa parcialmente en el conocimiento pertinente cerrando así el círculo argumental.

El conocimiento científico acerca del "entorno" (condicionantes actuales para ubicar correctamente una propuesta de desarrollo) y acerca del "interno" (factores actuales del crecimiento y del desarrollo), constituyen simples insumos para la cuestión central en materia de desarrollo territorial; ¿cómo intervenir de manera eficiente? La acumulación de conocimiento debe permitir a la propia comunidad preparar una rutina de trabajo que permita elaborar la propuesta que, en la perspectiva desarrollada acá, no es sino un proyecto político regional o un proyecto colectivo o societal de futuro. No es suficiente, cuando se pretende responsabilizar a la propia sociedad civil de la preparación de la propuesta, seguir usando términos de menor complejidad, como "plan regional" o como "estrategia regional", no por cuestio- 
nes puristas, sino simplemente porque ambos conceptos corresponden a contextos de muchísima menor complejidad social, contextos caracterizados por el control absoluto del medio por un solo agente (el Estado, en la vieja planificación normativa) o por la hegemonía ejercida nuevamente por un solo agente en un medio en el cual comparte poder (el Estado, en las versiones más contemporáneas de la planificación desde el sector público). Ahora se trata de trabajar con una multiplicidad de agentes, con diversas racionalidades (no sólo con la racionalidad económica), con paradigmas constructivistas, con inter-subjetividades, con recursos no materiales imposibles de ser tratados con criterios económicos, creando espacios en donde el lenguaje, las conversaciones y las formas de comunicación superan a los cálculos de porcentajes, tasas, coeficientes, etc.

Si bien la práctica de la cooperación y del trabajo colectivo se inventa a sí misma, Boisier en por lo menos dos oportunidades (1992 y 1995) ha escrito propuestas metodológicas que ayuden en "el difícil arte de hacer región". En el Brasil hay también propuestas metodológicas novedosas en relación al Nordeste (Proyecto ARIDAS) y en relación al Estado de Ceará, esta última muy influenciada por el pensamiento de $\mathrm{E}$. Deming.

Un asunto que estas ideas ayudan a poner en su verdadera dimensión tiene que ver con la complejidad y con las dificultades de la coordinación, en cualquier situación real. No es difícil, para fines ilustrativos, imaginar que alrededor de una "mesa sinergética" se han reunido, por ejemplo, 200 actores de significación regional. Supóngase que esta reunión tiene lugar a fines de un año cualquiera y que se pide a cada actor explicitar el abanico de opciones decisionales que enfrenta para el año siguiente; imagínese que cada actor da a conocer sólo cinco opciones o cursos de acción independientes. La cuestión ahora consiste en cómo transformar estas 1.000 opciones en una matriz decisional coherente con la propuesta de futuro, que allí mismo se ha elaborado. Ni la coordinación política ni la de mercado pueden resolver este gigantesco problema en la forma deseada. Lechner (1997), a partir de trabajos de Messner, propone la coordinación en red en contextos como el mostrado acá. El mismo Lechner sostiene que actualmente es a través de redes que se negocian planes de desarrollo regional. Un problema para ello, en América Latina, radica en el inadecuado nivel de confianza que regula las relaciones sociales, en circunstancias que la coordinación mediante redes se basa precisamente en la confianza.

Si se contrastan estas propuestas metodológicas con la práctica de preparación de los documentos regionales de desarrollo en cada una de las trece regiones chilenas actuales, las carencias son evidentes, sin que ello subvalore el trabajo hecho, en gran medida sin que medie, desde el Estado y sus organismos, procesos previos de creación y difusión de conocimiento. Pero queda mucho camino por recorrer.

En síntesis, la globalización como un fenómeno amplio y sistémico, producirá, por sí mismo una variedad de impactos y efectos territoriales en cada país. Cada país puede adoptar una actitud pasiva frente a ellos, lo que no es muy sabio, ya que ello significa minimizar lós beneficios y maximizar los costos; a la inversa, cada país puede adoptar una actitud proactiva, que procure invertir los términos de la situación, maximizando beneficios y minimizando costos. Esta actitud supone intervenir inteligentemente sobre ciertos procesos; esta intervención asume la modalidad concreta de políticas: de alcance regional/nacional en una mano, y de fomento al crecimiento y al desarrollo de cada región, en la otra. Presuponen el partenariado activo entre el Estado y la 
sociedad civil en su expresión territorial y se basan en el conocimiento pertinente de las cuestiones territoriales y regionales, es decir, en el conocimiento capaz de revelar la complejidad estructural sistémica del funcionamiento del territorio y de cada región. Hay entonces, siempre, una epistemología a construir para estar en la red y para saber estar.

Teorias y metáforas, en definitiva, porque esa ha sido la tónica de los trabajos personales del autor, desde ¿Qué hacer con la planificación regional antes de la medianoche? en 1977, hasta El vuelo de una cometa: una metáfora para una teoría del desarrollo territorial en 1997, y desde Diseño de planes regionales en 1976, hasta En busca del esquivo desarrollo regional: entre la "caja negra" y el proyecto político en 1996. Teorías y metáforas porque la ciencia puede ir de la mano con la poesía, en beneficio precisamente del conocimiento.

\section{BIBLIOGRAFIA}

Bennis, W. "Convertirse en lider de líderes", en A. Gibson (ed.) Repensando el futuro, Grupo Editorial NORMA, Santafé de Bogotá, 1997.

Boisier, S. El difícil arte de hacer región. CBC, Cusco, Perú, 1992. La mesoeconomía territorial: interacción entre personas e instituciones. ILPES/DPPR, Serie Ensayos, Doc. 95/26, Santiago de Chile, 1995. La política regional en América Latina bajo el signo de la globalización. DEBATES N 12, IPEA/FKA, Brasilia, 1996/a.

Boisier S. En busca del esquivo desarrollo regional. Entre la caja negra y el proyecto politico. PLANEJAMENTO E POLITICAS PUBLICAS N 13, IPEA, Brasilia, 1996/b. EI vuelo de una cometa. Una metáfora para una teoria del desarrollo territorial. REVISTA EURE $N^{\circ} 69$, IEU/U. Gatólica de Chile, Santiago de Chile, 1997.

Costa-Filho A. GlobalicaA $\hat{A}_{n}$ e Politicas Regionais Nacionaisna América Latina. DEBATES № 12, IPEA/FKA, Brasilia, 1996.

Ferrer A. Historia de la globalización. F.C.E. México, 1997

Godoy P. EI MERCOSUR y la pedagogia. Diario LA EPOCA, 15/7/97, Santiago de Chile.

Gutierrez E., Ortiz J. Villamil "Planificación de sistemas abiertos", EL TRIMESTRE ECONOMICO, N2 149 , Mexico, 1971.

Hirschmann, A.O. Strategy of Economic Development. Yale University Press, New Haven, 1958
Ianni O. Teoria de la globalización. Siglo XXI Editores, México, 1996.

Izam, M. Evolución, análisis y perspectivas del mercado Común del Sur. CEPAL/IUC, LC/R.1706, Santiago de Chile, 1997.

Lechner, N. Tres formas de coordinación social. REVISTA de la CEPAL N² 61, Santiago de Chile, 1997.

Lira, L. Regionalismo abierto y regionalismo virtual. ILPES DPPR, Serie Investigaciones, Doc. 95/13, Santiago de Chile, 1994.

Lira, L. Información y conocimiento para el análisis regional conducente a la toma de decisiones, ILPES/DPPR, Doc. 97/38, Serie Ensayos Santiago de Chile, 1997.

Mora, Z. Educación para la competitividad productiva. Universidad del Bio-Bio, CEUR, Concepción, Chile, 1997.

Naisbitt , J. "De naciones-Estados a redes", en R. Gibson (ed.), op.cit.

Peyrefitte, A. La sociedad de la confianza. Editorial Andrés Bello, Santiago de Chile, 1996.

Putnam, R. Making democracy work: civic traditions in modern Italy. Princeton University Press, USA, 1993.

Richard, N. Globalización e identidades culturales. Centro EL CANELO, Santiago de Chile, 1996.

Vaillant, M. Pradera, Frontera y puerto, otra vez. Montevideo, 1997. 